Rev. Elet. em Gestão, Educação e Tecnologia Ambiental (e-ISSN: 2236-1170)

\title{
CONSUMO DE CARNES POR ESTUDANTES DOS DIFERENTES CENTROS DE ENSINO DA UNIVERSIDADE FEDERAL DE SANTA MARIA, RS, BRASIL
}

\section{Meat consumption by students of different educational institutions of the Federal University of Santa Maria, RS, Brazil}

\author{
Jackeline Karsten Kirinus ${ }^{1}$, Edom de Avila Fabricio ${ }^{2}$, Ana Paula Burin Fruet ${ }^{3}$, Andréa Cristina Dörr ${ }^{4}$, Renius \\ de Oliveira Mello ${ }^{5}$, José Laerte Nörnberg ${ }^{6}$ \\ ${ }^{1}$ Universidade Federal de Santa Maria (UFSM) - Aluna de doutorado do Programa de Pós-graduação em Ciência e Tecnologia de \\ Alimentos: jackeline.kirinus@gmail.com \\ ${ }^{2}$ UFSM - Aluno do curso de Zootecnia: edomfabricio@hotmail.com \\ ${ }^{3}$ UFSM - Aluna de mestrado do Programa de Pós-graduação em Ciência e Tecnologia de Alimentos. E-mail: ap burin@hotmail.com \\ ${ }^{4}$ UFSM - Profa. Adjunto do Departamento de Ciências Econômicas: andreadoerr@yahoo.com.br \\ ${ }^{5}$ UFSM - Prof. Adjunto do Departamento de Tecnologia e Ciência dos Alimentos: reniusmello@gmail.com \\ ${ }^{6}$ UFSM - Prof. Associado do Departamento de Tecnologia e Ciência dos Alimentos: jlnornberg@gmail.com
}

http://dx.doi.org/10.5902/223611708716

\section{RESUMO}

O objetivo deste estudo foi determinar quais são os tipos de carnes mais consumidos pelos alunos dos diferentes centros de ensino da Universidade Federal de Santa Maria (UFSM), Rio Grande do Sul, Brasil. A coleta ocorreu no período de março a abril de 2011 por meio da técnica de amostragem para a coleta dos dados primários através de formulários aplicados aos estudantes de graduação da UFSM. O estudo piloto realizada revelou um desvio padrão de 0,275 quilogramas de carne consumida e um erro amostral de $5 \%$, desta forma o tamanho total da amostra foi de 125 estudantes entrevistados, em um intervalo de confiança de $95 \%$. Do total de entrevistados, $77 \%$ consomem mais a carne bovina, $20 \%$ a de frango, $2 \%$ a de peixes, e $1 \%$ consomem mais a carne suína. Foi verificado que a carne bovina é mais consumida pelos estudantes dos diferentes centros de ensino da UFSM e que a carne ovina foi escolhida com última opção de consumo pelos discentes da instituição.

Palavras-chave: carne bovina, carne de frango, questionários, ingestão

\begin{abstract}
This study aims to determine which types of meats consumed more by students of different educational institutions of the Universidade Federal de Santa Maria (UFSM), Rio Grande do Sul, Brazil. The collection took place from March to April 2011 through the sampling technique for the collection of primary data through forms applied to graduate students UFSM. The pilot study conducted revealed a standard deviation of $0.275 \mathrm{~kg}$ of meat consumed and a sampling error of $5 \%$, thus the total sample size of 125 students were interviewed, with a confidence interval of $95 \%$. Of the total respondents, $77 \%$ consume more beef, chicken $20 \%$ to $2 \%$ of the fish, and $1 \%$ consume more swine. It was found that beef is most commonly used by students of different learning centers UFSM and the lamb was chosen last option for consumption by students of the institution.
\end{abstract}

Keywords: beef, chicken, questionnaires, intake 
Rev. Elet. em Gestão, Educação e Tecnologia Ambiental (e-ISSN: 2236-1170)

\section{INTRODUÇÃO}

No Brasil, a bovinocultura de corte representa grande importância econômica. Segundo previsões do USDA (2012) a produção brasileira de carne bovina cresceu $64,75 \%$ nos últimos 20 anos, passando de 5,48 milhões de toneladas em 1991 para 9,03 milhões de toneladas em 2011. E ao que tudo indica, em 2013, deverá aumentar 2,5\% (aproximadamente 9,4 milhões de toneladas) consolidando-se tanto como produtora de alimento nobre para o mercado interno, como elemento importante para o país por sua inserção no mercado mundial de carne bovina principalmente devido à demanda internacional e a um pequeno aumento na demanda doméstica.

Também, segundo o USDA (2012) é previsto um aumento de 3\% no rebanho bovino brasileiro em 2013, principalmente devido ao suporte financeiro do Governo para a reconstrução do rebanho bovino, melhoramento genético, renovação das pastagens e preços sustentados do gado. Dessa forma, o rebanho bovino deverá alcançar quase 210 milhões de cabeças até o final do ano.

O setor bovino forma hoje uma importante cadeia do agronegócio, com forte interação dos setores ligados ao agronegócio, genética, comércio, cultura e turismo, sendo uma das cadeias produtivas que mais oferece oportunidades de trabalho, conquistando posição de destaque na economia nacional e mundial (MAPA, 2011a). Para manter a posição de um dos maiores exportadores de carne bovina mundial e conquistar novos mercados, é importante que o setor produtivo seja competitivo, fornecendo produtos de qualidade a preços acessíveis, sendo necessário para isso, melhorar, entre outros fatores, a eficiência de produção e a qualidade do produto (VENERONI, 2010).

As fontes mais freqüentes de abastecimento de carne são as espécies de animais domésticos como bovinos, suínos, e aves, e em menor medida, búfalos, ovinos, e caprinos. Em 2011, o consumo per capita de carnes aumentou em relação ao ano anterior chegando a 37,4 kg para carne bovina; 43,9 kg de carne de aves e 14,1 kg de carne suína, refletindo o bom desempenho da economia brasileira (MAPA, 2011b). Neste sentido, segundo Levi-Costa et al. (2005) as carnes bovina, frango, suína, peixes e ovina possuem uma participação de $14,3 \%$ no total de calorias do consumo domiciliar do na região Sul do Brasil.

Atualmente, a sociedade vem passando por muitas transformações que se estendem às esferas políticas, econômicas, culturais, sociais e tecnológicas, o que tem gerado novas tendências de mercado, afetando o perfil do consumidor de carnes e o seu padrão de consumo (SCHLUTER \& LEE, 1999; REGMI \& GEHLTHAR, 2001).

Desta forma, alguns produtos têm seu consumo influenciado pela substituição de outros, o que pode ser verificado em relação as carnes bovinas e de frango. Esta realidade tratase de uma disputa mercadológica pela preferência do consumidor.

A cidade de Santa Maria possui um total de 261.031 habitantes (IBGE, 2010). Os estudantes de graduação da Universidade Federal de Santa Maria (UFSM) somam 12.496 (DERCA/PROGRAD) e este número representa aproximadamente $5 \%$ da população da cidade. Assim, o objetivo deste trabalho foi determinar quais são os tipos de carnes mais consumidos pelos alunos dos diferentes centros de ensino da Universidade Federal de Santa Maria, Rio Grande do Sul, Brasil. 
REGExtIFSM

KIRINUS et all, v(11), no 11, p. 2511-2517, JUN, 2013.

Rev. Elet. em Gestão, Educação e Tecnologia Ambiental (e-ISSN: 2236-1170)

\section{METODOLOGIA}

Para a realização deste trabalho foi utilizada a técnica de amostragem em uma pesquisa de campo com coleta de dados primários através de formulários aplicados aos estudantes de graduação da UFSM. Anteriormente à definição da amostra para a coleta efetiva dos dados, foi realizada uma pesquisa piloto compreendendo um conjunto de 30 estudantes a fim de obter informações sobre a população em análise e determinar o tamanho mínimo da amostra necessária para a pesquisa, visando-se um nível de confiança de $95 \%$. Para a amostragem, o cálculo do tamanho da amostra é dado conforme Schneider (2004).

Os alunos de graduação da UFSM totalizaram 12.496 estudantes matriculados no primeiro semestre de 2010 (DERCA/PROGRAD) ${ }^{1}$. Os alunos de graduação foram separados pelos 8 centros de concentração da UFSM e o Colégio Politécnico que compreendem cursos em áreas relacionadas, distribuindo-se da seguinte maneira: Centro de Artes e Letras (CAL, 1091 estudantes); Centro de Ciências Naturais e Exatas (CCNE, 1484 estudantes); Centro de Ciências Rurais (CCR, 1888 estudantes); Centro de Ciências da Saúde (CCS, 1958 estudantes); Centro de Ciências Sociais e Humanas (CCSH, 2997 estudantes); Centro de Educação (CE, 781 estudantes); Centro de Educação Física e Desporto (CEFD, 534 estudantes); Centro de Tecnologia (CT, 1763 estudantes); e Colégio Politécnico (CP, 375 estudantes).

O tamanho da amostra ideal para cada centro de ensino da UFSM foi calculado e está distribuído proporcionalmente pelos estratos conforme representado na Tabela 1. A pesquisa piloto foi realizada com 30 estudantes, e apresentou um desvio-padrão de 0,275 quilogramas de carne e um erro amostral de 5\%, desta forma o tamanho total da amostra foi de 125 estudantes entrevistados, com um intervalo de confiança de $95 \%$.

Tabela 1. População, proporção e amostra para cada centro de ensino da UFSM

\begin{tabular}{llll}
\hline CENTRO & MATRÍCULAS 2010/I & PROPORÇÃO (\%) & AMOSTRA \\
\hline CAL & 1091 & 8,5 & 11 \\
CCNE & 1484 & 11,5 & 14 \\
CCR & 1888 & 14,7 & 18 \\
CCS & 1958 & 15,2 & 19 \\
CCSH & 2997 & 23,3 & 29 \\
CE & 781 & 6,1 & 08 \\
CEFD & 534 & 4,1 & 05 \\
CT & 1763 & 13,7 & 17 \\
CP & 375 & 2,9 & 04 \\
\hline
\end{tabular}

${ }^{1}$ Foram excluídos do total dos estudantes de graduação da UFSM os referentes ao Centro de Educação Superior Norte (CESNORS) em Frederico Westphalen e Palmeira das Missões, e à Unidade Descentralizada de Educação Superior de Silveira Martins (UDESSM). 


\section{REGEXfUFSM}

KIRINUS et all, v(11), no 11, p. 2511-2517, JUN, 2013.

Rev. Elet. em Gestão, Educação e Tecnologia Ambiental (e-ISSN: 2236-1170)

\begin{tabular}{llll}
\hline TOTAL & 12871 & 100,0 & 125 \\
\hline
\end{tabular}

Fonte: Elaborado pelos autores com base nos dados do DERCA/PROGRAD (2010).

Com o objetivo de alcançar a proposta da pesquisa foi feita a seguinte pergunta aos entrevistados: "Enumere por ordem de prioridade as três principais carnes que você consome, (exemplo: 1, 2, 3): ( ) Gado, ( ) Frango, ( ) Porco, ( ) Peixe, ( ) Ovelha".

\section{RESULTADOS E DISCUSSÃO}

O percentual de entrevistados, separados pelos centros de ensino da UFSM, que consomem mais cada tipo de carne estão demonstrados na Tabela 2, verificou-se que 2 (1,6\%) dos 125 entrevistados não consome nenhum tipo de carne, estes foram excluídos da análise dos dados. Foi constatada uma variação no consumo dos diferentes centros de ensino, os resultados da pesquisa não explicam essa variação, mas se relacionam com dados existentes na literatura.

Do total de entrevistados, $77 \%$ consomem mais a carne bovina, $20 \%$ a de frango, $2 \%$ a de peixes, e $1 \%$ consomem mais a carne suína, contrastando com os dados obtidos pelo MAPA (2011) para o consumo brasileiro, onde o consumo per capita anual para o ano de 2010 da carne de frango $(43,9 \mathrm{~kg})$ foi maior que o de carne bovina $(37,4 \mathrm{~kg})$ e suína $(14,1 \mathrm{~kg})$.

Pode-se observar que $100 \%$ dos entrevistados alocados nos centros de ensino CCR e Colégio Politécnico consomem mais a carne bovina. Este resultado pode estar relacionado ao fato de que os estudantes dos cursos pertencentes as Ciências Agrárias são na maioria oriundos do meio rural, onde é comum o abate de bovinos para o consumo.

Tabela 2. Proporção de alunos que consomem preferencialmente as carnes de bovino, frango, suíno, peixe e ovino nos respectivos centros de ensino da UFSM

\begin{tabular}{llllll}
\hline CENTRO & BOVINO & FRANGO & SUINO & PEIXE & OVINO \\
\hline CCSH, \% & $76(22 / 29)$ & $21(6 / 29)$ & $3(1 / 29)$ & $0(0 / 29)$ & $0(0 / 29)$ \\
CCR, \% & $100(18 / 18)$ & $0(0 / 18)$ & $0(0 / 18)$ & $0(0 / 18)$ & $0(0 / 18)$ \\
CE, \% & $63(5 / 8)$ & $38(3 / 8)$ & $0(0 / 8)$ & $0(0 / 8)$ & $0(0 / 8)$ \\
CAL, \% & $82(9 / 11)$ & $18(2 / 11)$ & $0(0 / 11)$ & $0(0 / 11)$ & $0(0 / 11)$ \\
CT, \% & $76(13 / 17)$ & $24(4 / 17)$ & $0(0 / 17)$ & $0(0 / 17)$ & $0(0 / 17)$ \\
CCS, \% & $72(13 / 18)$ & $22(4 / 18)$ & $0(0 / 18)$ & $6(1 / 18)$ & $0(0 / 18)$ \\
\hline
\end{tabular}


Rev. Elet. em Gestão, Educação e Tecnologia Ambiental (e-ISSN: 2236-1170)

\begin{tabular}{llllll}
\hline CEFD, \% & $50(2 / 4)$ & $50(2 / 4)$ & $0(0 / 4)$ & $0(0 / 4)$ & $0(0 / 4)$ \\
CCNE, \% & $64(9 / 14)$ & $29(4 / 14)$ & $0(0 / 14)$ & $7(1 / 14)$ & $0(0 / 14)$ \\
CP, \% & $100(4 / 4)$ & $0(0 / 4)$ & $0(0 / 4)$ & $0(0 / 4)$ & $0(0 / 4)$ \\
TOTAL, \% & $77(95 / 123)$ & $20(25 / 123)$ & $1(1 / 123)$ & $2(2 / 123)$ & $0(0 / 123)$ \\
\hline
\end{tabular}

Fonte: Elaborado pelos autores com base nos dados obtidos na pesquisa.

No CEFD o consumo dos alunos é dividido, $50 \%$ deles consomem mais a carne bovina e $50 \%$ a carne de frango, nenhum entrevistado citou outra carne como mais consumida. Sugere-se que os discentes do CEFD tenham uma maior preocupação com a ingestão de gordura na alimentação, e recorrem à carne de frango por acreditarem que esta contém menores teores de lipídios.

Por ordem de prioridade foi observado, respectivamente, um crescente consumo de carne de frango nos centros de ensino CAL, CCSH, CT, CCS, CCNE e CE. No entanto, esta ordem decresce para o consumo de carne bovina, indicando uma alta relação de substituição entre estes dois tipos de carnes. Neto (2010) mostra que houve um crescimento no consumo per capita das carnes bovinas e frango pelos brasileiros nos últimos 10 anos, embora este aumento tenha sido superior na carne de frango, devido ao menor preço em relação à bovina.

A carne de peixe foi citada somente nos centros CCS (6\%) e CCNE (7\%) como primeira opção. Foi verificado que $39 \%$ dos estudantes consomem a carne de peixes como uma terceira opção.

A carne suína não tem um consumo muito elevado entre os estudantes da UFSM, somente no $\mathrm{CCSH}, 3 \%$ dos entrevistados optaram por ela como primeira opção. Este resultado contrasta com o consumo mundial observado pela Food and Agriculture Organization (2011), em que $36 \%$ da carne consumida é de origem suína. Segundo Schlindwein \& Kassouf (2006) o menor consumo de carne suína em relação ao consumo de carne bovina e frango é atribuído principalmente a dois fatores: a importância que a população atribui aos mitos relacionados a prováveis impactos negativos do consumo da carne suína sobre a saúde, e a falta de cortes específicos de baixo valor agregado (acessíveis à população de baixa renda).

$\mathrm{Na}$ ordem de preferência, a carne ovina ficou em última opção, pois nenhum dos entrevistados a consomem em primeiro lugar. No entanto, $11 \%$ destes a citaram como terceira escolha, evidenciando uma baixa popularidade frente aos consumidores deste extrato da população. Este resultado pode ser comprovado por um estudo realizado por Porto (2004), em que o consumo de carne ovina foi considerado caro e eventual.

Deste modo, segundo Viana \& Silveira (2009) pode ser observado no Rio Grande do Sul, que fatores como: a sazonalidade produtiva da ovinocultura, a inexistência de um mercado 


\section{REGEJATFSM}

KIRINUS et all, v(11), no 11, p. 2511-2517, JUN, 2013.

Rev. Elet. em Gestão, Educação e Tecnologia Ambiental (e-ISSN: 2236-1170)

constante, a exigência de uma oferta regular de animais, a necessidade de escala para comercialização e a busca por animais jovens por parte dos frigoríficos são dificuldades enfrentadas pelos produtores na comercialização de animais para abate, tornando a cadeia da carne ovina menos competitiva.

\section{CONCLUSÕES}

Foi verificado que a carne bovina é mais consumida pelos estudantes dos diferentes centros de ensino da UFSM. Os entrevistados do CCR e Colégio Politécnico apresentaram maior consumo de carne bovina, já o CEFD foi o centro que apresentou o maior consumo de frango. Os entrevistados do CCSH foram os únicos a optarem por carne suína como primeira opção. Somente o CCS e CCNE escolheram a carne de peixe como primeira opção. A carne ovina foi escolhida com última opção de consumo pelos discentes da UFSM.

\section{REFERÊNCIAS BIBLIOGRÁFICAS}

BARBETTA, P. A. Estatística Aplicada às Ciências Sociais. 7. ed. Florianópolis: Editora da UFSC, 2008. 315 p.

DERCA/PROGRAD. Departamento de Registro e Controle Acadêmico/Pró-Reitoria de Graduação. Estatísticas. Disponível em: <http://www.ufsm.br/derca/>. Acesso em: 01 abr. 2011.

FAO. Food and Agriculture Organization. Divisão de produção e sanidade animal. Fontes de carne. Disponível em: <http://www.fao.org/ag/againfo/themes/es/meat/backgr_sources.html>. Acesso em: 15 jul. 2011. IBGE. Instituto Brasileiro de Geografia e Estatística. Cidades. Santa Maria. Disponível em: <http://www.ibge.gov.br/cidadesat/topwindow.htm?1>. Acesso em: 01 jul. 2011.

LEVY-COSTA, R. B. et al. Disponibilidade domiciliar de alimentos no Brasil: distribuição e evolução (1974-2003). Revista Saúde Pública, v. 39, n. 4, p. 530-540, 2005.

MAPA. MINISTÉRIO DA AGRICULTURA PECUÁRIA E ABASTECIMENTO. Bovinos e Bubalinos. 2011a. Disponível em: <http://www.agricultura.gov.br/animal/especies/bovinos-e-bubalinos>. Acesso em: 15 mai. 2012.

MAPA. Ministério da Agricultura Pecuária e Abastecimento. Animal. Mercado Interno. 2011b. Disponível em: <http://www.agricultura.gov.br/animal/mercado-interno>. Acesso em: 15 jul. 2011.

NETO, A. D. B. Posicionamento estratégico do setor de carnes de caprinos e ovinos no mercado de carnes brasileiro. Revista Tecnologia \& Ciência Agropecuária, v. 4, n. 4, p. 81-85, 2010. 


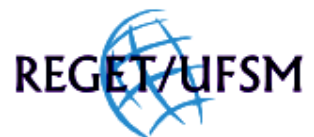

KIRINUS et all, v(11), no 11, p. 2511-2517, JUN, 2013.

Rev. Elet. em Gestão, Educação e Tecnologia Ambiental (e-ISSN: 2236-1170)

PORTO, R. G. Consumidor final de carnes: características e hábitos em Pelotas, RS. Serviço de Informação da Carne. Disponível em: <http://www.sic.org.br/PDF/Pesquisa_Pelotas.pdf>. Acesso em: 15 jul. 2011.

REGMI, A.; GEHLTHAR, M. Consumer preferences and concerns shape global food trade. Food Review, v. 24, n. 3, p. $2-8,2001$.

SCHNEIDER, L. Estimativa dos Gastos dos Alunos da UFSM (2002): Aplicação da Amostragem Estratificada Proporcional. Santa Maria: UFSM, 2004. Monografia (Especialização em Estatística e Modelagem Quantitativa do Departamento de Estatística), Universidade Federal de Santa Maria, 2004.

SCHLUTER, G.; LEE, C. Changing food consumption patterns: their effect on the U.S. food system, 1972-1992. Food Review, v. 22, n. 2, p. 35-37, 1999.

SCHLINDWEIN, M. M.; KASSOUF, A. L. Análise da influência de alguns fatores socioeconômicos e demográficos no consumo domiciliar de carnes no Brasil. Revista de Economia e Sociologia Rural, v. 44, n. 3, p. 549-572, 2006.

USDA. UNITED STATES DEPARTMENT OF AGRICULTURE. Foreign Agricultural Service: Global Agricultural Information Network. Washington, D.C., 2012a. Online. Disponível em:

<http://gain.fas.usda.gov/Recent\%20GAIN\%20Publications/Livestock\%20and\%20Products\%20Semi-

annual_Brasilia_Brazil_1-3-2012.pdf>. Acesso em: 09 mar. 2012.

VENERONI, G. B. Associação de snps em genes candidatos e de regiões cromossômicas com espessura de gordura subcutânea em bovinos da raça canchim. São Carlos: UFSCAR, 2010. 140f. Tese (Doutorado em genética e evolução), Universidade Federal de São Carlos, 2010.

VIANA J. G. A.; SILVEIRA V. C. P. Análise econômica da ovinocultura: estudo de caso na Metade Sul do Rio Grande do Sul, Brasil. Ciência Rural, v. 39, n. 4, p. 1187-1192, 2009. 